\title{
Development and validation of an environmental heat strain risk assessment (EHSRA) index using structural equation modeling based on empirical relations
}

\author{
Saeid Yazdanirad ${ }^{1}$ (D) Farideh Golbabaei ${ }^{1 *}$ (D), Abbas Rahimi Foroushani², Mohammad Reza Monazzam ${ }^{1}$ and
} Habibollah Dehghan ${ }^{3}$

\begin{abstract}
Background: Need to a simple, available, accurate, comprehensive, and valid indicator is felt to assess thermal effects. Therefore, the present study was aimed to develop and validate the environmental heat strain risk assessment (EHSRA) index using structural equation modeling (SEM) based on empirical relations.

Methods: This cross-sectional study was performed on 201 male workers in environments with various climatic conditions. The heart rate and tympanic temperature of the individuals were monitored at times of 30,60, and 90 min after beginning the work. At these times, values of dry temperature, wet temperature, globe temperature, and air velocity were also measured and metabolism rate and clothing thermal insulation value were estimated. At the end, a theoretical model was depicted in AMOS software and obtained coefficients were applied to develop a novel index. The scores of this indicator were categorized into four risk levels via ROC curves and validate using linear regression analysis.

Results: Indirect effect coefficients of the globe temperature, dry temperature, wet temperature, air velocity, metabolism, and clothing thermal insulation variables on the tympanic temperature were computed by $0.77,0.75,0.69,0.24,0.49$, and 0.39 , respectively. These coefficients were applied to develop the index. Optimal cut-off points of boundaries between risk levels included 12.02, 15.88, and 17.56. The results showed that the EHSRA index justified 75\% of the variations of the tympanic temperature $\left(R^{2}=0.75\right)$.
\end{abstract}

Conclusions: The novel index possesses appropriate validity. It was suggested that this indicator is applied and validated in various environments in the next studies.

Keywords: Heat stress, Risk assessment, Structural equation modeling, Empirical index

\section{Background}

People occupied in industrial environments are exposed to many hazards to threaten their health. Heat is one of the most prominent physical harmful agents in workplaces. Nearly $40 \%$ of the world's people live in the warm and hot

\footnotetext{
* Correspondence: fgolbabaei@tums.ac.ir

1 Department of Occupational Health Engineering, School of Public Health, Tehran University of Medical Sciences, Tehran, Iran

Full list of author information is available at the end of the article
}

climatic regions of the earth, where normal daytime temperatures are higher than $30{ }^{\circ} \mathrm{C}$ at most days of a year [1]. In these zones, numerous workers are performing routine tasks. Global warming will increase adverse thermal effects on bodily health [2]. The results of several studies show that air temperature may raise from 1.1 to $6.4{ }^{\circ} \mathrm{C}$ at the end of the twenty-first century compared to the nineteenth century [3]. Additionally, processes in some industries such as cement, steel, casting, and food produce and diffuse heat

(c) The Author(s). 2020 Open Access This article is licensed under a Creative Commons Attribution 4.0 International License, which permits use, sharing, adaptation, distribution and reproduction in any medium or format, as long as you give appropriate credit to the original author(s) and the source, provide a link to the Creative Commons licence, and indicate if changes were made. The images or other third party material in this article are included in the article's Creative Commons licence, unless indicated otherwise in a credit line to the material. If material is not included in the article's Creative Commons licence and your intended use is not permitted by statutory regulation or exceeds the permitted use, you will need to obtain permission directly from the copyright holder. To view a copy of this licence, visit http://creativecommons.org/licenses/by/4.0/. The Creative Commons Public Domain Dedication waiver (http://creativecommons.org/publicdomain/zero/1.0/) applies to the data made available in this article, unless otherwise stated in a credit line to the data. 
because of energy conversions and weak insulation [4]. The elevated temperature associated with humid conditions and intense physical activity also increases the risk [5]. The excessive exposure of workers can cause health problems such as fatigue, headache, muscle cramps, weakness, dizziness, nausea, vomiting, tachycardia, hypotension, syncope, progressive loss of mental alertness, stroke, and even death [6]. Although consequences of work under hot and humid conditions threat bodily health in developed countries, this problem is much more serious in developing and low- to middle-income countries such as Iran because of the existence of aged industries, weak control measures, densely populated environments, high physical workloads, and weak safety regulations [7].

To prevent heat effects, the fundamental effective agents in producing thermal strain must be assessed, so that through controlling them heat-related illnesses can be reduced. In total, the body heat balance is determined by six substantial factors, including four climatic )dry temperature, radiant temperature, humidity rate, and air velocity( and two non-climatic )clothing and physical workload( variables [8]. Imbalance of these factors impresses on physiological parameters, so-called thermal strain, and results in the occupational illnesses [9]. In fact, the body dissipates heat through dry and evaporative losses [10]. An environment with high air and radiant temperatures disrupt the dry mechanism and an ambiance with excessive humidity impairs the evaporative mechanism. Therefore, the heat produced by physical activity cannot easily be transferred from the body to the external environment [5]. The air movement also moderates this exchange. The effect of air velocity depends on dry temperature so that if the temperature is lower than skin temperature, increased air velocity reduces the strain, otherwise enhances it [11]. Moreover, clothing characterization such as thermal insulation and evaporative resistance influence this balance and can limit the transition [12]. An index must consider all stated six factors for comprehensively and appropriately assessing the occupational heat stress [13]. Many indicators have been designed to evaluate it. Freitas and Grigorieva conducted a study to identify and investigate numerous thermal climate indices and ultimately found 165 indicators, of which a few of them such as predicted heat strain (PHS) involve all six variables [14]. Other properties of a desirable index include simplicity, availability, accuracy, validity, reliability, and repeatability. Havenith and Filad investigated 35 heat stress indicators and models. They concluded that simple indices are most popular in the field and complex models appear to be limited in use [15]. Rational indicators such as PHS involve complex equations for calculating thermal strain while empirical indices possess more simplicity. Additionally, an index must have good validity and reliability for predicting the thermal strain. Wet bulb global temperature (WBGT), as an empirical indicator, is among the most widely used in many countries and there is an international standard of ISO 7243 based on it [16]. However, this index is being outdated after 60 years of use and has been criticized by some authors [17]. As well as many indices have not appropriately categorized and interpreted the risk of thermal strain. Need to a simple, available, accurate, comprehensive, and valid indicator is felt. Therefore, the present study was aimed to develop and validate the environmental heat strain risk assessment (EHSR A) index using structural equation modeling (SEM) based on empirical relations.

\section{Methods \\ Participants}

This cross-sectional study was performed on 201 male workers, including 111 subjects from a steel industry located in Isfahan province of Iran as a hot and dry environment and 90 persons from a petrochemical industry placed in Bandar abbas province of Iran as a hot and humidity ambiance. The main difference between the two industries was the climatic conditions so that the petrochemical industry had higher relative humidity. After visiting various departments in each of the above industries, desired tasks and workstations were carefully selected based on the environmental parameters and physical workload. Subsequently, the 400 individuals employed in these parts were invited to the study and evaluated. Based on the criteria, 199 persons were excluded and 201 subjects remained in the study. Inclusion criteria consisted of work experience higher than one year in a warm environment, absence of mental, infectious, pulmonary, cardiovascular, hypertension, renal, hyperthyroidism, digestive, and diabetes diseases, absence of musculoskeletal disorders, non-consumption of medications affecting heart rate and blood pressure such as beta-blockers, phenothiazines, diuretics, anticholinergics, antispasmodics, psychotropics, antihistamines, antihypertensives, amphetamine, and decongestants, and non-consumption of coffee, caffeine, and alcohol from $12 \mathrm{~h}$ before the study. Additionally, their tympanic membrane and auditory canal were in a pleasant situation and lack of excessive wax. Exclusion criteria for participants in this research included unwillingness to impressively continue, lack of cooperation in accurate measurement of physiological parameters, heart rate higher than the value calculated in Eq. 1 (HRmax), and tympanic temperature above $39^{\circ} \mathrm{C}$.

$$
\operatorname{HRmax}=[208-(0.7 \times \text { age }(\text { year }))]
$$

\section{Data collection}

The protocol of this study was reviewed and approved by the Medical Ethics Committee of Tehran University of Medical Sciences (IR.TUMS.SPH.REC.1397.321). Each 
of the participants was invited to refer to a cool and quiet room at a certain time. In the referral day, the person filled out the consent form developed by the medical ethics committee, and his demographical data, including age, workstation, physical activity, and work experience was collected. Height and weight were carefully measured using a tape meter and a digital scale. After that, the individual was invited to rest and relax on a bed in the room for $30 \mathrm{~min}$. His heart rate and tympanic temperature were properly measured at times of 20,25, and $30 \mathrm{~min}$ based on the standard of ISO 9886. At the next step, the person was asked to return to his workplace and start the routine tasks without resting during the test. The physiological parameters of the individual were accurately monitored at times of 30,60 , and 90 min after beginning the work based on the standard of ISO 9886. At these times, environmental climatic parameters, including dry temperature $\left(T_{\mathrm{a}}\right)$, wet temperature $\left(T_{\mathrm{w}}\right)$, globe temperature $\left(T_{\mathrm{g}}\right)$, and air velocity $\left(V_{\mathrm{a}}\right)$ were also measured based on standards of ISO 7243 and ISO 7726. As well as, the mean value of metabolism rate $\left(M_{\mathrm{t}}\right)$ was estimated by the standard of ISO 8996 and corrected by the standard of BS 7243. To determine clothing thermal insulation $\left(I_{\mathrm{c}}\right)$, the standard of ISO 9920 was applied. It should be noted that each of the thermal and physiological variables was recorded at three times. The mean values of thermal variables and the highest values of physiological variables were considered as representative values.

\section{Instruments}

The tympanic temperature, as the gold standard, was measured using a tympanic thermometer of Braun thermoscan IRT 6530 with an accuracy of 0.1 degrees of centigrade. This device has been registered as a patent with prewarmed tips and an exact positioning system, which increases the validity and accuracy of measurements. Various studies investigated the reliability of this thermometer for measuring the tympanic temperature. Navarro et al. concluded Braun thermoscan IRT 6530 reliably estimates the body temperature during exercise in the heat [18]. To measure the heart rate, pulse monitor with chest strap of Beurer PM70 model with an accuracy of one beat per minute was also applied. Environmental climatic parameters, including dry temperature, wet temperature, and globe temperature were monitored using WBGT meter of TES $1369 \mathrm{~B}$ with an accuracy of $0.1^{\circ}$ of centigrade. The air velocity was separately screened using TES 1340 with an accuracy of $0.01 \mathrm{~m} / \mathrm{s}$. Height and weight were also measured using a tape meter with an accuracy of $0.01 \mathrm{~m}$ and a digital scale of Hamilton with an accuracy of $0.1 \mathrm{~kg}$, respectively.

\section{Index development}

After designing the model in AMOS software, the indirect effect values of six main parameters in changing tympanic temperature were used as variable coefficients in the novel index. Before writing the final formula, each of the variables was normalized between 0 and 1 based on values measured in the present study. Equation 2 shows the relation used to compute the novel index.

$$
\begin{aligned}
\text { EHSRA } & =\left[\left(C_{1} \times T_{a n}\right)+\left(C_{2} \times T_{w n}\right)+\left(C_{3} \times T_{g n}\right)\right. \\
& \left.+\left(C_{4} \times V_{a n}\right)+\left(C_{5} \times M_{t n}\right)+\left(C_{6} \times I_{c n}\right)\right]
\end{aligned}
$$

Where $C_{1}$ to $C_{6}$ shows effect coefficients of fundamental variables, $T_{a n}$ is normalized dry temperature, $T_{w n}$ is normalized wet temperature, $T_{g n}$ is normalized globe temperature, $V_{a n}$ is normalized air velocity, $M_{t n}$ is normalized total metabolism, and $I_{c n}$ is normalized clothing thermal insulation.

\section{Statistical analyses}

Ultimately, data were entered into the statistical package for the social sciences (SPSS) version 18. Descriptive analyses were performed. After that, the normality of variables was investigated using skew and kurtosis curves in AMOS. Based on the results, all of them showed normal distributions. Hence, correlations were calculated using the Pearson test. Based on the relationships among variables, an empirical model was depicted in AMOS software. Its fitness was evaluated using three groups of absolute, comparative, and normed fit indices. In the model, factor loading values of critical variables on heat strain (latent variable) and tympanic temperature (gold standard variable) were calculated. Subsequently, based on these results, the novel index was developed. In final, the total score of the index was categorized into four risk levels from low to very high using Receiver operator curves (ROC) analysis. In ROC analysis, tympanic temperatures of $37.5,38.0$, and $38.5{ }^{\circ} \mathrm{C}$ were considered as boundaries between risk levels [19]. To discover optimal cut-off points of the index, the nearest point to the ideal state in each of the ROC curves was used. To investigate the validity of the index, a linear regression analysis was performed between the EHSRA index and tympanic temperature.

\section{Results}

Table 1 represents the local climatic information. Moreover, Table 2 shows the statistical distribution of demographics parameters, fundamental factors, and physiological parameters. Skew and kurtosis curves revealed that the studied variables had normal distributions. Based on the results, each of the variables encompassed the extensive range of values that the model requires. As well as, the fundamental factors could produce the variations in tympanic temperature from 36.7 to $39.1{ }^{\circ} \mathrm{C}$. Table 3 also reports the correlation matrix of the studied variables. There were 
Table 1 The local climatic information

\begin{tabular}{|c|c|c|c|c|c|c|}
\hline \multirow[t]{2}{*}{ Parameter } & \multicolumn{3}{|c|}{ Steel industry } & \multicolumn{3}{|c|}{ Petrochemical industry } \\
\hline & Range & Mean & Standard deviation & Range & Mean & Standard deviation \\
\hline Dry temperature (degree of centigrade) & $21.97-43.60$ & 33.58 & 5.21 & $24.10-48.20$ & 36.26 & 6.61 \\
\hline Wet temperature (degree of centigrade) & $12.10-24.17$ & 17.63 & 2.04 & $13.97-37.57$ & 27.43 & 6.26 \\
\hline Globe temperature (degree of centigrade) & $23.40-62.43$ & 39.01 & 9.63 & $24.10-57.23$ & 40.97 & 9.80 \\
\hline Relative humidity (\%) & $9.01-39.31$ & 19.60 & 9.92 & $14.82-79.11$ & 52.09 & 17.71 \\
\hline
\end{tabular}

significant relationships between tympanic temperature and all fundamental factors $(P<0.01)$. The highest correlation coefficients with tympanic temperature were related to variables of the globe, dry, and wet temperatures with values of $0.766,0.751$, and 0.685 , respectively.

Figure 1 shows the theoretical model of the present study analyzed using SEM. Based on this model, the heat strain produced by six main variables possesses factor loading of 0.80 on tympanic temperature. Moreover, Table 4 reports the direct and indirect effects of fundamental factors on the variations of tympanic temperature. The variables of the globe, dry, and wet temperatures with the coefficients of $0.77,0.75$, and 0.69 indicated the highest indirect effects on the tympanic temperature, respectively. Table 5 also represents the goodness-of-fit indices of the theoretical model of the present study. The results demonstrated that all obtained values of goodness-of-fit indices are in optimal ranges.

The environmental heat stress assessment risk (EHSR A) index was developed by indirect effect coefficients and normalized variables as follows:

$$
\begin{aligned}
\text { EHSRAI } & =10 \times\left[0.752 \times\left(\frac{T_{a}-21.97}{26.23}\right)+0.686\right. \\
& \times\left(\frac{T_{w}-12.10}{25.47}\right)+0.774 \times\left(\frac{T_{g}-23.40}{39.30}\right) \\
& +0.244 \times\left(\frac{V_{a}-0.0}{4.20}\right)+0.491 \times\left(\frac{M_{t}-130}{360}\right) \\
& \left.+0.387 \times\left(\frac{I_{c}-0.50}{0.85}\right)\right]
\end{aligned}
$$

Where $T_{a}$ is dry temperature (degree of centigrade), $T_{w}$ is wet temperature (degree of centigrade), $T_{g}$ is globe temperature (degree of centigrade), $V_{a}$ is air velocity (meter per second), $M_{t}$ is total metabolism (Watts), and $I_{c}$ is clothing thermal insulation (Clo). It is important to note that when dry temperature is lower than normal skin temperature $\left(35{ }^{\circ} \mathrm{C}\right)$, the sign of air velocity

Table 2 Statistical distribution of demographics parameters, fundamental factors, and physiological parameters

\begin{tabular}{lllll}
\hline Variable & & Range & Mean & Standard deviation \\
\hline Demographics parameters & Age (years) & $22-55$ & 36.62 & 8.24 \\
& Weight (kg) & $55.70-123.00$ & 80.52 & 14.91 \\
& Height (m) & $1.61-1.90$ & 1.76 & 0.06 \\
& Body mass index (kilogram per square meter) & $19.23-34.94$ & 26.06 & 4.07 \\
& Physical activity (hours per week) & $0-12$ & 2.14 & 2.47 \\
& Work experience (year) & $1-40$ & 12.72 & 7.85 \\
& Dry temperature (degree of centigrade) & $21.97-48.20$ & 24.78 & 6.01 \\
Fundamental factors & Wet temperature (degree of centigrade) & $12.10-37.57$ & 22.01 & 6.60 \\
& Globe temperature (degree of centigrade) & $23.40-62.43$ & 39.89 & 9.73 \\
& Air velocity (meter per second) & $0-4.20$ & 0.58 & 0.39 \\
& Total metabolism (watts) & $130-490$ & 248.47 & 103.70 \\
& Clothing thermal resistance (clo) & $0.50-1.35$ & 0.83 & 0.14 \\
Physiological parameters & Resting tympanic temperature (degree of centigrade) & $36.7-37.4$ & 37.01 & 0.15 \\
& Working tympanic temperature (degree of centigrade) & $36.7-39.1$ & 37.7 & 0.56 \\
& Resting heart rate (beat/min) & $64.00-94.00$ & 76.14 & 5.99
\end{tabular}


Table 3 Correlation matrix of the studied variables

\begin{tabular}{lllllll}
\hline Variables & $\mathbf{1}$ & $\mathbf{2}$ & $\mathbf{3}$ & $\mathbf{4}$ & $\mathbf{5}$ & $\mathbf{6}$ \\
\hline Dry temperature & - & & & & \\
Wet temperature & $0.626^{* *}$ & - & & & \\
Globe temperature & $0.907^{* *}$ & $0.511^{* *}$ & - & & & \\
Air velocity & $0.296^{* *}$ & $0.152^{*}$ & $0.347^{* *}$ & - & 0.082 & - \\
Total metabolism & $0.318^{* *}$ & 0.131 & $0.332^{* *}$ & 0.135 & $0.321^{* *}$ & - \\
Clothing thermal insulation & $0.454^{* *}$ & 0.054 & $0.530^{* *}$ & $0.258^{* *}$ & $0.509^{* *}$ & $0.388^{* *}$ \\
\hline Tympanic temperature & $0.751^{* *}$ & $0.685^{* *}$ & $0.766^{* *}$ & -
\end{tabular}

(1) Dry temperature, (2) wet temperature, (3) globe temperature, (4) air velocity, (5) total metabolism, (6) clothing thermal insulation, (7) tympanic temperature ${ }^{* *} P<0.01$

${ }^{*} P<0.05$

coefficient changes from positive to negative because it decreases heat strain in these conditions.

Fig. 2a-c displays receiver operating characteristic (ROC) curves related to low and moderate risk zones, of moderate and high risk zones, and high and very high risk zones, respectively. Based on the results, optimal cut-off points of boundaries between low and moderate risk zones, between moderate and high risk zones, and between high and very high zones included 12.02 (sensitivity $=0.963$ and specificity $=0.840), 15.88$ (sensitivity $=0.945$ and specificity $=0.884$ ), and 17.56 (sensitivity $=0.938$ and specificity $=0.811$ ), respectively. Table 6 addresses the risk levels and equivalent scores of the EHSRA index. The area under of ROC curves (AUC), as a global summary statistic of diagnostic accuracy, in Fig. 2a, Fig. 2b, and Fig. 2c were 0.961 (95\% CI $0.939,0.983)(P<0.001), 0.950$ (95\% CI $0.922,0.978)(P<0.001)$, and 0.921 (95\% CI $0.875,0.967)$ $(P<0.001)$, respectively. Furthermore, a linear regression analysis was performed between the developed index and tympanic temperature to investigate its validity. Figure 3 illustrates the linear regression curve between the tympanic temperature and the EHSRA index. The results showed that the EHSRA index justified $75 \%$ of the tympanic temperature variable $\left(R^{2}=0.75\right)$.

\section{Discussion}

To develop the EHSRA index, several important properties of a desirable indicator, including comprehensiveness, simplicity, and validity were considered. The index involved all fundamental effective variables in producing the heat strain, including dry temperature, wet temperature, globe temperature, air velocity, metabolism, and clothing thermal resistance. Results also indicated that heat strain produced by these fundamental parameters possess a direct effect with a factor loading of 0.80 on tympanic temperature. This reveals that the

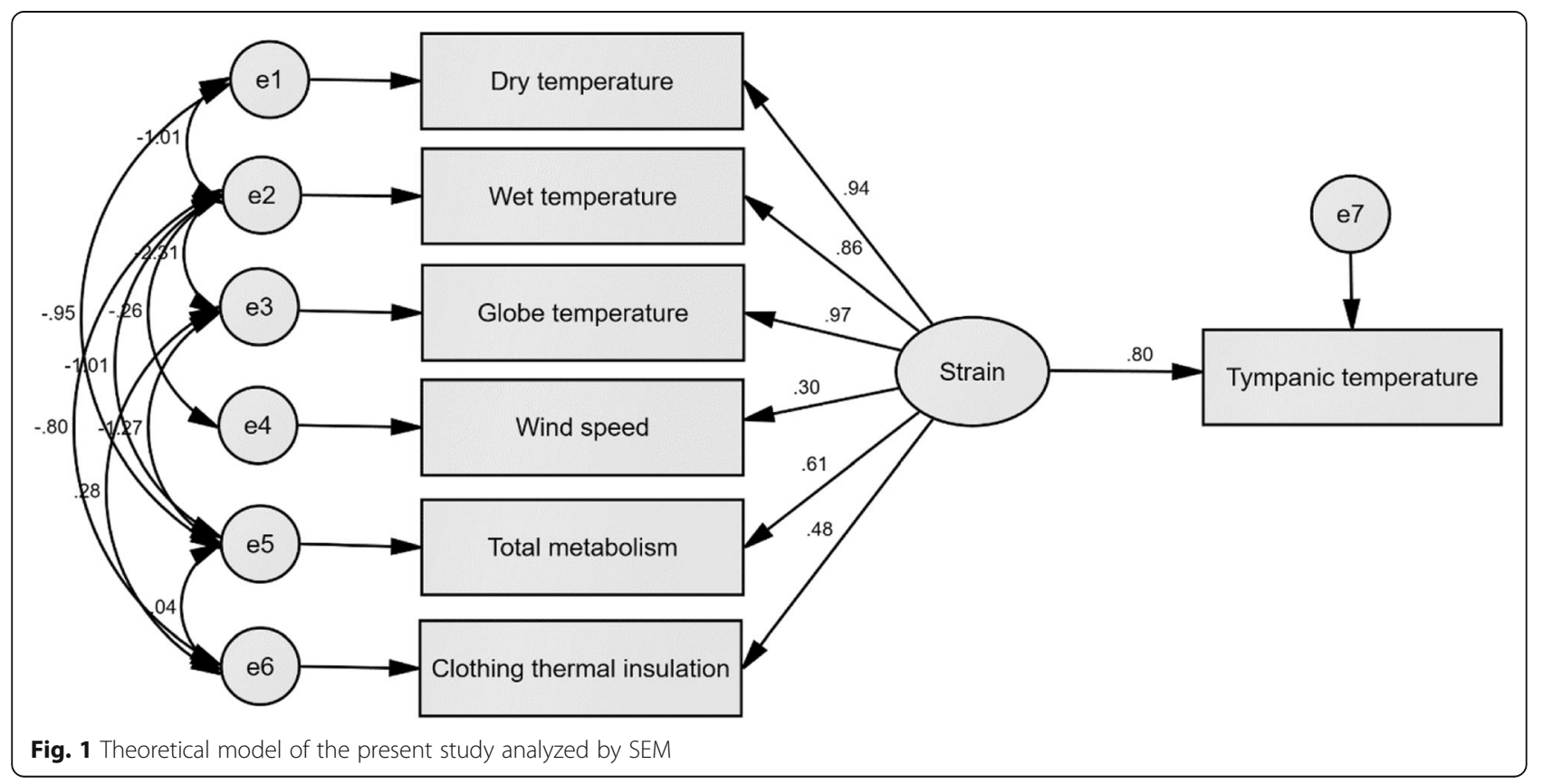


Table 4 Direct and indirect effects of fundamental factors on the variations of tympanic temperature

\begin{tabular}{llll}
\hline Variables & Direct effect & Indirect effect & $P$ value \\
\hline Dry temperature & 0.939 & 0.752 & $P<0.001$ \\
Wet temperature & 0.857 & 0.686 & $P<0.001$ \\
Globe temperature & 0.966 & 0.774 & $P<0.001$ \\
Air velocity & 0.305 & 0.244 & $P<0.001$ \\
Total metabolism & 0.613 & 0.491 & $P<0.001$ \\
Clothing thermal insulation & 0.483 & 0.387 & $P<0.001$ \\
Thermal strain & 0.801 & - & $P<0.001$ \\
\hline
\end{tabular}

novel index can significantly predict the tympanic temperature. However, its prediction with higher accuracy requires more numbers of variables. Additionally, it was attempted to measure the extensive range of conditions in the industries and occupations. The values range of fundamental factors shows that the novel index can be applied in a variety of warm and hot workplaces.

Based on the results, the indirect effect coefficients of the globe temperature, dry temperature, wet temperature, air velocity, metabolism, and clothing thermal insulation variables were equal to $0.77,0.75,0.69,0.24,0.49$, and 0.39 , respectively. These coefficients were used to develop the EHSRA index. Dehghan et al also developed an observational-perceptual indicator using SEM, as named heat strain score index (HSSI). Coefficients of air temperature, wet temperature, air velocity, metabolism, and clothing thermal insulation consisted of $0.76,0.65,0.62$, 0.64 , and 0.31 , respectively [20]. The coefficients of some parameters in the EHSRA index such as air temperature, wet temperature, and clothing thermal insulation obtained approximately similar to those in HSSI. However, variables of air velocity and metabolism showed significantly different coefficients. It may be due to observational-perceptual evaluation in the study of Dehghan et al. compared to environmental assessment in the present research. Also, a comparison of coefficients in the EHSRA index with those in some indices shows that there is a difference. In WBGT, as a valid heat stress indicator, wet temperature (0.7), global temperature (0.2), and dry temperature (0.1) possess the highest weights, respectively [21]. Liang et al. (2011) constructed a new environmental heat stress index using Cox regression. Weights of wet and dry temperatures calculated by 0.62 and 0.38 , respectively [19]. Wet temperature compared to the globe and dry temperatures possess a lower variation range. For this reason, in WBGT and Liang et al indicator, the coefficient value of wet temperature is higher than that of the globe and dry temperatures. If the values of these temperatures are normalized and their variation range be equal, the coefficient of wet temperature decreases, and the coefficients of dry and globe temperatures increase. Also, high globe and air temperatures enhance thermal absorption through the convection and radiation mechanisms and produce a difficult condition to lose heat, while the high relative humidity diminishes the ability of sweat evaporation from the skin [22]. Hence, the moisture cannot affect thermal strain until the sweating mechanism is activated. For example, high humidity in low air and radiant temperatures cannot cause the heat strain. Perhaps for this reason, the coefficient of wet temperature obtained the value lower than that of dry and globe temperatures in the present study. The effect of parameters of air velocity, metabolism, and clothing thermal insulation in producing the heat strain also depends on stated environmental variables. Therefore, it seems that smaller impact coefficients of them are logical. Air velocity showed the lowest impact coefficient among fundamental factors. This parameter was often unstable in studied environments, which decreases its effects on the heat strain. Moreover, the impact of air velocity is controlled by the air temperature. So that if the dry temperature is lower than normal skin temperature, the air velocity decreases the heat strain, otherwise increases it [11].

After developing the EHSRA index, its calculated scores were categorized into four risk levels using ROC. The area under ROC (AUC) related to different risk levels consisted of $0.961,0.950$, and 0.921 . The values of AUC greater than 0.90 indicate excellent diagnostic accuracy of curves [23]. Therefore, the scores can be easily and accurately interpreted based on this classification.

Table 5 Goodness-of-fit indices of the theoretical model of the present study

\begin{tabular}{llll}
\hline Indices & Name & Fitness & Obtained value \\
\hline Absolute fitness indices & Goodness-of-fit index (GFI) & $>0.9$ & 0.991 \\
& Adjusted goodness-of-fit index (AGFI) & $>0.9$ & 0.947 \\
Comparative fitness indices & Normed fit index (NFI) & $>0.9$ & 0.992 \\
& Comparative fit index (CFI) & $>0.9$ & 0.998 \\
Normed fit index & Incremental fit index (IFI) & $<0.1$ & 0.998 \\
& Root mean squared error of approximation (RMSEA) & $1-3$ & 0.043 \\
$P$ value & Normed Chi-square (X2/df) & $>0.05$ & 1.364 \\
\hline
\end{tabular}




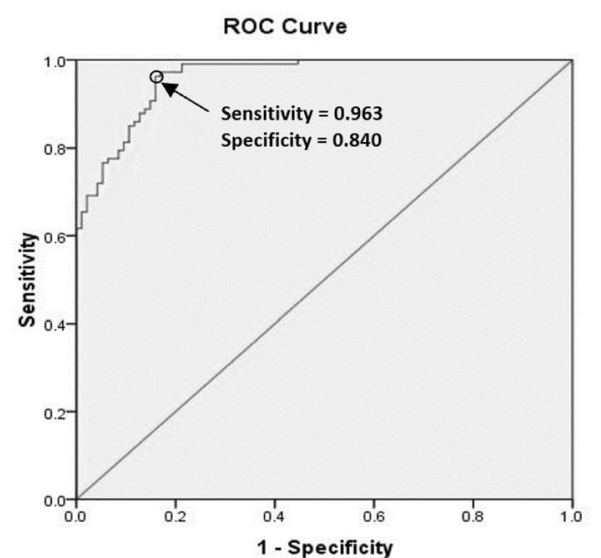

(a)

Roc Curve

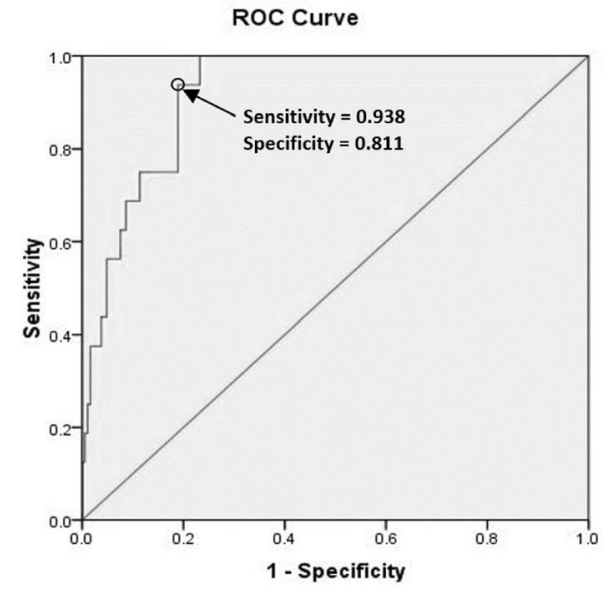

(c)

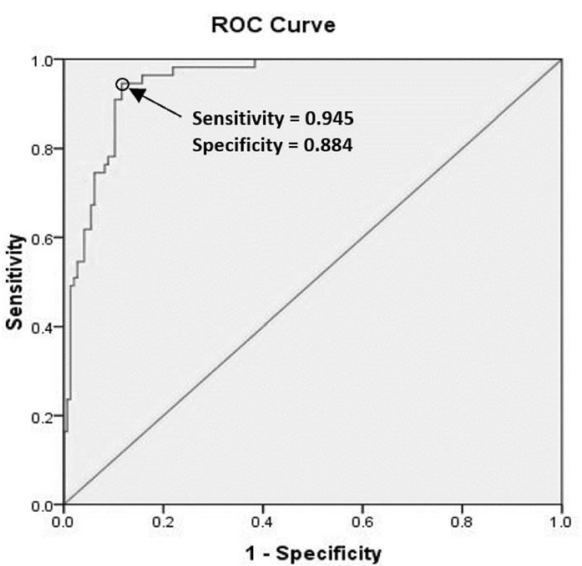

(b) 


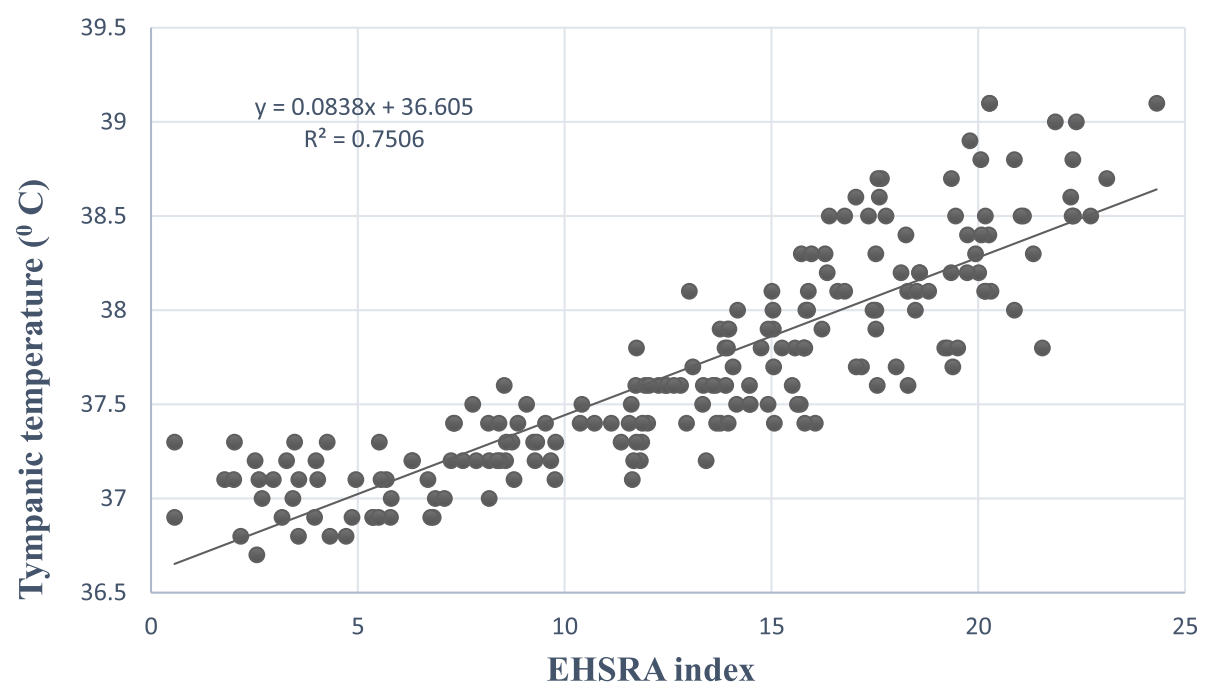

Fig. 3 Linear regression curve between tympanic temperature and EHSRA index

\section{Conclusion}

In this study, a novel heat stress assessment index was developed using the main effective factors in producing the thermal strain. The results showed variables of globe temperature, dry temperature, and wet temperature possess the greatest effect coefficients, respectively. Based on the results, the novel index has appropriate validity. It is suggested that this index is applied and validated in various environments in future studies.

\section{Abbreviations}

WBGT: Wet bulb global temperature; PHS: Predicted heat strain; EHSRA: Environmental heat strain risk assessment; SEM: Structural equation modeling; ROC: Receiver operator curves

\section{Acknowledgements}

The authors appreciate the participants in this study.

\section{Authors' contributions}

SY collected the data and contributed to the manuscript. FG designed the study and wrote the manuscript. ARF carried out the statistical analyses of the data. MRM and HD were involved in the interpretation of the data, and the coordinator researcher. All authors read and proved the final manuscript.

\section{Funding}

This study, as a Ph.D. thesis, entitled "development and validation of thermal risk assessment indices based on modeling of effective factors in producing heat strain resulted from measurement, observation and perception methods" has been supported by Tehran University of Medical Sciences \& Health Services grant number 9421138003 . The funding body has played no role in the design of the study, collection of data, analysis of data, and interpreting results or in writing the manuscript or in decision to submit the manuscript for publication. The content of this publication is only the responsibility of the authors.

\section{Availability of data and materials}

All data generated and analyzed during this step of study are included in this published article.

\section{Ethics approval and consent to participate}

The protocol was reviewed and approved by the Medical Ethics Committee of Tehran University of Medical Sciences (IR.TUMS.SPH.REC.1397.321). All steps of the study were in accordance with the ethical standards. All participants were asked to fill out the consent form developed by the medical ethics committee, and written informed consent was obtained from all of them.

\section{Consent for publication}

Not applicable

\section{Competing interests}

The authors declare that they have no conflict of interest.

\section{Author details}

${ }^{1}$ Department of Occupational Health Engineering, School of Public Health, Tehran University of Medical Sciences, Tehran, Iran. ${ }^{2}$ Department of Epidemiology and Biostatistics, School of Public Health, Tehran University of Medical Sciences, Tehran, Iran. ${ }^{3}$ Department of Occupational Health Engineering, School of Public Health, Isfahan University of Medical Sciences, Isfahan, Iran.

Received: 22 June 2020 Accepted: 14 September 2020

Published online: 28 October 2020

\section{References}

1. Lowry SJ, Blecker H, Camp J, De Castro B, Hecker S, Arbabi S, et al. Possibilities and challenges in occupational injury surveillance of day laborers. Am J Ind Med. 2010;53(2):126-34.

2. Spector JT, Sheffield PE. Re-evaluating occupational heat stress in a changing climate. Ann Occup Hyg. 2014;58(8):936-42.

3. Ficklin DL, Luo Y, Luedeling E, Zhang M. Climate change sensitivity assessment of a highly agricultural watershed using SWAT. J Hydrol. 2009; 374(1-2):16-29.

4. Lundgren K, Kuklane K, Gao C, Holmer I. Effects of heat stress on working populations when facing climate change. Ind Health. 2013;51(1):3-15.

5. Parsons K. Human thermal environments: the effects of hot, moderate, and cold environments on human health, comfort, and performance: CRC press; 2014.

6. Crowe J, Nilsson M, Kjellstrom T, Wesseling C. Heat-Related symptoms in sugarcane harvesters. Am J Ind Med. 2015;58(5):541-8.

7. Kjellstrom T, Crowe J. Climate change, workplace heat exposure, and occupational health and productivity in Central America. Int J Occup Environ Health. 2011;17(3):270-81.

8. Kjellstrom T, Holmer I, Lemke B. Workplace heat stress, health and productivity-an increasing challenge for low and middle-income countries during climate change. Glob Health Action. 2009;2(1):2047.

9. Becker JA, Stewart LK. Heat-related illness. Am Fam Physician. 2011;83:11.

10. O'Brien C, Blanchard LA, Cadarette BS, Endrusick TL, Xu X, Berglund LG, et al. Methods of evaluating protective clothing relative to heat and cold stress: 
thermal manikin, biomedical modeling, and human testing. J Occup Environ Hyg. 2011;8(10):588-99.

11. Northington WE, Suyama J, Goss FL, Randall C, Gallagher M, Hostler D. Physiological responses during graded treadmill exercise in chemical-resistant personal protective equipment. Prehosp Emerg Care. 2007;11(4):394-8.

12. Ming $F$, Wenguo $W$, Xuefeng $H$. Experimental investigation of the thermal insulation and evaporative resistance of protective clothing on a thermal manikin in a hot environment. J Tsinghua Uni. 2017;57(3):281-5,92.

13. Epstein $Y$, Moran DS. Thermal comfort and the heat stress indices. Ind Health. 2006;44(3):388-98.

14. de Freitas CR, Grigorieva EA. A comparison and appraisal of a comprehensive range of human thermal climate indices. Int J Biometeorol. 2017;61(3):487-512.

15. Havenith G, Fiala D. Thermal indices and thermophysiological modeling for heat stress. Comprehensive Physiology. 2011;6(1):255-302.

16. ACGIH. TLVs for chemical substances and physical agents and Biological exposure indicators. Cincinatti: American Conference of Government Industrial Hygienists; 2009.

17. Gao C, Kuklane K, Östergren P-O, Kjellstrom T. Occupational heat stress assessment and protective strategies in the context of climate change. Int J Biometeorol. 2018;62(3):359-71.

18. Morán-Navarro R, Courel-Ibáñez J, Martínez-Cava A, Conesa-Ros E, SánchezPay A, Mora-Rodriguez R, et al. Validity of skin, oral and tympanic temperatures during exercise in the heat: effects of wind and sweat. Ann Biomed Eng. 2019:47(1):317-31.

19. Liang C, Zheng G, Zhu N, Tian Z, Lu S, Chen Y. A new environmental heat stress index for indoor hot and humid environments based on Cox regression. Build Environ. 2011;46(12):2472-9.

20. Dehghan H, Mortzavi SB, Jafari MJ, Maracy MR. Development and validation of a questionnaire for preliminary assessment of heat stress at workplace. J Res Health Sci. 2015;15(3):175-81.

21. Budd GM. Wet-bulb globe temperature (WBGT) —its history and its limitations. J Med Sci Sports. 2008;1 1(1):20-32.

22. McLellan TM, Daanen HA, Cheung SS. Encapsulated environment. Compr Physiol. 2013;3(3):1363-91.

23. Akobeng AK. Understanding diagnostic tests 3: receiver operating characteristic curves. Acta Paediatr. 2007;96(5):644-7.

24. Monazzam M, Golbabaei F, Hematjo R, Hosseini M, Nassiri P, FahangDehghan S. Evaluation of DI, WBGT, and SWreq/PHS heat stress indices for estimating the heat load on the employees of a petrochemical industry. Int J Occup Hyg. 2014;6(1):6-10.

25. Malchaire J. Occupational heat stress assessment by the predicted heat strain model. Ind Health. 2006:44(3):380-7.

26. Falahati M, Alimohammadi I, Farshad A, Zokaii M, Sardar A. Evaluating the reliability of WBGT and P4SR by comparison to core body temperature. Iran Occup Health. 2012;9(3):22-31.

\section{Publisher's Note}

Springer Nature remains neutral with regard to jurisdictional claims in published maps and institutional affiliations.

Ready to submit your research? Choose BMC and benefit from:

- fast, convenient online submission

- thorough peer review by experienced researchers in your field

- rapid publication on acceptance

- support for research data, including large and complex data types

- gold Open Access which fosters wider collaboration and increased citations

- maximum visibility for your research: over $100 \mathrm{M}$ website views per year

At $\mathrm{BMC}$, research is always in progress.

Learn more biomedcentral.com/submissions 